Research Article

Human and Medical Genetics

\title{
Characterization of the 3'UTR of the BTD gene and identification of regulatory elements and microRNAs
}

\author{
Gerda Cristal Villalba Silva ${ }^{1,2}$ (D), Taciane Borsatto ${ }^{2,3}$, Ida Vanessa Doederlein Schwartz ${ }^{1,2,4}$ (D) \\ and Fernanda Sperb-Ludwig ${ }^{1,2}$ (D) \\ ${ }^{1}$ Universidade Federal do Rio Grande do Sul, Programa de Pós-Graduação em Genética e Biologia \\ Molecular, Porto Alegre, RS, Brazil. \\ ${ }^{2}$ Hospital de Clínicas de Porto Alegre, Centro de Pesquisa Experimental, Laboratório BRAIN, Porto Alegre, \\ RS, Brazil. \\ ${ }^{3}$ Hospital de Clínicas de Porto Alegre, Porto Alegre, RS, Brazil. \\ ${ }^{4}$ Universidade Federal do Rio Grande do Sul, Departamento de Genética, Porto Alegre, RS, Brazil.
}

\begin{abstract}
Reduced biotinidase activity is associated with a spectrum of deficiency ranging from total deficiency to heterozygous levels, a finding that is not always explained by the pathogenic variants observed in the $B T D$ gene. The investigation of miRNAs, regulatory elements and variants in the 3'UTR region may present relevance in understanding the genotype-phenotype association. The aims of the study were to characterize the regulatory elements of the 3'UTR of the BTD gene and identify variants and miRNAs which may explain the discrepancies observed between genotype and biochemical phenotype. We evaluated 92 individuals with reduced biotinidase activity (level of heterozygotes $=33$, borderline $=35$, partial $\mathrm{DB}=20$ or total $\mathrm{DB}=4$ ) with previously determined BTD genotype. The 3'UTR of the $B T D$ gene was Sanger sequenced. In silico analysis was performed to identify miRNAs and regulatory elements. No variants were found in the 3'UTR. We found 97 possible miRNAs associated with the BTD gene, 49 predicted miRNAs involved in the alanine, biotin, citrate and pyruvate metabolic pathways and 5 genes involved in biotin metabolism. Six AU-rich elements were found. Our data suggest variants in the 3'UTR of BTD do not explain the genotype-phenotype discrepancies found in Brazilian individuals with reduced biotinidase.
\end{abstract}

Keywords: 3'UTR, genetic variants, miRNAs, AU-rich elements, biotinidase.

Received: November 20, 2020; Accepted: August 22, 2021.

\section{Introduction}

The enzyme biotinidase (EC 3.5.1.12), encoded by the $B T D$ gene, catalyzes the cleavage of biocytin into the vitamin biotin, which acts as a cofactor for several carboxylases, such as pyruvate carboxylase, propionyl-CoA carboxylase, 3-methylcrotonyl-CoA carboxylase, and acetyl-CoA carboxylases 1 (alpha) and 2 (beta) (Wolf, 2001).

The BTD gene is composed by four exons, and its 3'UTR has $331 \mathrm{bp}$ (ENST00000383778.5). The corresponding mRNA has two potential start codons (AUG) (Stanley et al., 2004, Pindolia et al., 2010). There are 17 different 3'UTR lengths with sizes ranging from 77 to $8226 \mathrm{pb}$, variable according to the transcript. The $B T D$ gene has a constitutive expression pattern and healthy individuals present expression between 0.5 and $1.5 \log 10$ transcripts per million (Figure 1). The threedimensional structure of biotinidase as predicted by in silico modeling consists of two domains (Pindolia et al., 2007).

Biotinidase deficiency (BD) is a metabolic disease, inherited in an autosomal recessive pattern, disabling the body to assimilate biotin from the diet and inhibiting biotin recycling (Baumgartner and Suormala, 2012). If not treated

Send correspondence to Ida Vanessa Doederlein Schwartz. Hospital de Clínicas de Porto Alegre, Rua Ramiro Barcelos, 2350, 90035-903, Porto Alegre, RS, Brazil. E-mail: ischwartz@ @cpa.edu.br. early, BD may lead to neurological and dermatological disorders (Wastell et al., 1988). BD may be total (activity $<10 \%$ of normal) or partial (10-30\%). There is an association between certain genotypes and the observed biochemical phenotype (total or partial), but in some patients, genotype and phenotype are mismatched. According to previous studies by our group, the association between the expected biochemical phenotype (according to genotype) and the actual biochemical phenotype occurs in $68.5 \%$ of cases, and variants in the $5^{\prime} \mathrm{UTR}$ of BTD do not seem to explain the variations found (Borsatto et al., 2014, 2017, 2019). Low activity of carboxylases can be found in BD and in Multiple Carboxylase Deficiency, a different disease caused by biallelic pathogenic variations in the HLCS gene, which encode the holocarboxylase synthetase enzyme (EC 6.3.4.10).

The aim of this study was to characterize the 3'UTR of the $B T D$ gene in individuals with reduced biotinidase activity previously described by our group (Borsatto et al., 2014, $2017,2019)$, and to identify which regulatory elements could influence the expression of biotinidase.

\section{Material and Methods}

The study was approved by the Research Ethics Committee of Hospital de Clínicas de Porto Alegre ( ${ }^{\circ} 16-$ 0480 and 12-0186), Brazil, and the subjects consented to participate by signing the Informed Consent Form. 

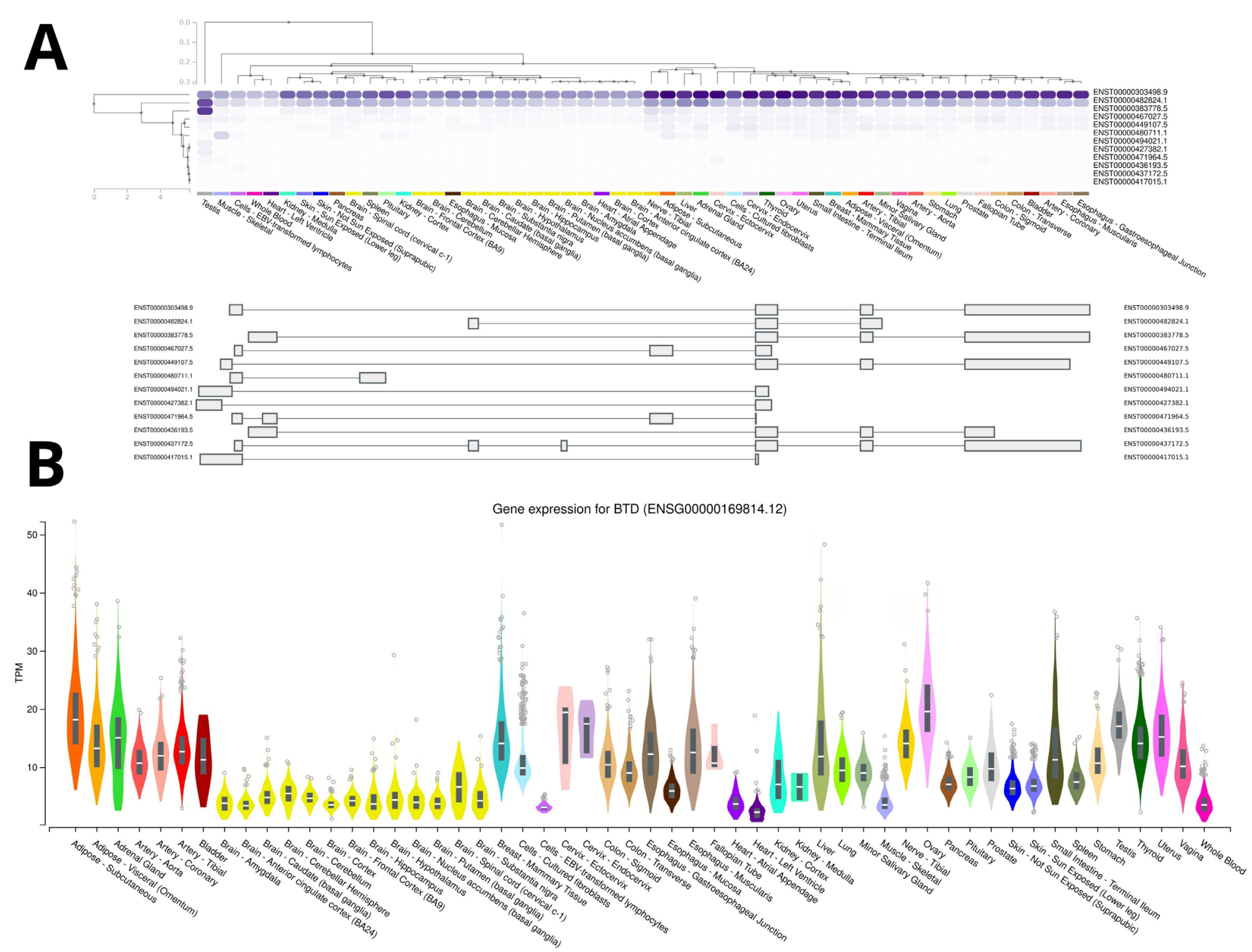

Figure 1 - BTD gene expression. A: Isoforms in human tissues. B: Expression pattern in several tissues and organs. Adapted from GTEx (https://www.gtexportal.org/home/). 
Ninety-two individuals with reduced biotinidase activity were included: 33 with heterozygous level; 19 with borderline partial/heterozygous; 16 with borderline heterozygous/normal; 20 with partial deficiency; and 4 with total deficiency. These patients had the exons, exon-intron junctions, and 5'UTR of $B T D$ previously sequenced, and were described by Borsatto et al. (2014) and Borsatto et al. (2017). The genotype and biochemical profile of the cohort is shown in Table 1, and details regarding the classification of the biochemical phenotype and $B T D$ sequencing can be found in Borsatto et al. (2014) and Borsatto et al. (2017). Eighteen individuals had an inconsistent genotype-biochemical phenotype association (1-6, 24-33, 86, 87 - Table 1).

For genomic DNA extraction, blood samples were collected in EDTA-containing tubes and processed using the Easy-DNA gDNA Purification kit (Thermo Fisher). The 3'UTR of the BTD gene was amplified by PCR with specific primers. The products were purified with $20 \%$ PEG $8000 / 2.5 \mathrm{M} \mathrm{NaCl}$

Table 1 - Genetic and biochemical profile of patients with reduced biotinidase activity included in the characterization of the 3'UTR.

\begin{tabular}{|c|c|c|c|c|c|c|}
\hline Patient & Allele 1 & Allele 2 & $\begin{array}{l}\text { Expected BD } \\
\text { according } \\
\text { to genotype }\end{array}$ & $\begin{array}{c}\text { Biotinidase } \\
\text { activity } \\
(\mathrm{nmol} / \mathrm{min} / \mathrm{mL})\end{array}$ & $\begin{array}{l}\text { Type of BD } \\
\text { according to } \\
\text { enzyme activity }\end{array}$ & Reference \\
\hline $1^{\#}$ & c.1330G>C (p.Asp444His) & $\begin{array}{c}\text { c. }[595 \mathrm{C}>\mathrm{A} ; 1413 \mathrm{~T}>\mathrm{C}]( \\
\text { p.Val199Met / p.Cys471Cys })\end{array}$ & Partial & 2.8 & $\mathrm{~Hz}$ & $\begin{array}{l}\text { Borsatto et al. } \\
\text { (2014) }\end{array}$ \\
\hline $2^{\#}$ & c. $[1330 \mathrm{G}>\mathrm{C} ; 643 \mathrm{C}>\mathrm{T}]^{*}$ & p.Asp444His / p.Leu215Phe* & Partial & 2.4 & $\mathrm{~Hz}$ & $\begin{array}{l}\text { Borsatto et al. } \\
\text { (2014) }\end{array}$ \\
\hline $3^{\#}$ & c.1330G>C (p.Asp444His) & c.511G >A (p.Ala171Thr) & Partial & 2.5 & $\mathrm{~Hz}$ & $\begin{array}{l}\text { Borsatto et al. } \\
\text { (2014) }\end{array}$ \\
\hline $4^{\#}$ & c.1330G>C (p.Asp444His) & c.755A > G (p.Asp252Gly) & Partial & 2.4 & $\mathrm{~Hz}$ & $\begin{array}{l}\text { Borsatto et al. } \\
\text { (2014) }\end{array}$ \\
\hline $5^{\#}$ & c.1330G>C (p.Asp444His) & c. $1629 \mathrm{C}>\mathrm{A}$ (p.Asp543Glu) & Partial & 2.5 & $\mathrm{~Hz}$ & $\begin{array}{l}\text { Borsatto et al. } \\
\text { (2017) }\end{array}$ \\
\hline $6^{\#}$ & c.1330G>C (p.Asp444His) & c.755A>G (p.Asp252Gly) & Partial & 3.03 & $\mathrm{~Hz}$ & $\begin{array}{l}\text { Borsatto et al. } \\
\text { (2017) }\end{array}$ \\
\hline 7 & c. $[1330 \mathrm{G}>\mathrm{C} ; 1629 \mathrm{C}>\mathrm{A}]^{*}$ & p.Asp444Hisp / Asp543Glu* & Partial / Hz & 2.6 & $\mathrm{~Hz}$ & $\begin{array}{l}\text { Borsatto et al. } \\
\text { (2014) }\end{array}$ \\
\hline 8 & $\begin{array}{c}\text { c. }[1330 \mathrm{G}>\mathrm{C} ; 511 \mathrm{G}>\mathrm{A}] \\
\text { (p.Asp444His / p.Ala171Thr) }\end{array}$ & c.1413T>C (p.Cys471Cys) & $\mathrm{Hz}$ & 3.3 & $\mathrm{~Hz}$ & $\begin{array}{l}\text { Borsatto et al. } \\
\text { (2014) }\end{array}$ \\
\hline 9 & c.1330G>C (p.Asp444His) & c.1330G >C (p.Asp444His) & $\mathrm{Hz}$ & 3.3 & $\mathrm{~Hz}$ & $\begin{array}{l}\text { Borsatto et al. } \\
\text { (2014) }\end{array}$ \\
\hline 10 & c.1330G>C (p.Asp444His) & c.1330G >C (p.Asp444His) & $\mathrm{Hz}$ & 4.6 & $\mathrm{~Hz}$ & $\begin{array}{l}\text { Borsatto et al. } \\
\text { (2017) }\end{array}$ \\
\hline 11 & c.1330G >C (p.Asp444His) & c. $1330 \mathrm{G}>\mathrm{C}$ (p.Asp444His) & $\mathrm{Hz}$ & 3.2 & $\mathrm{~Hz}$ & $\begin{array}{l}\text { Borsatto et al. } \\
\text { (2017) }\end{array}$ \\
\hline 12 & c.1330G >C (p.Asp444His) & c.1330G $>$ C (p.Asp444His) & $\mathrm{Hz}$ & 3.0 & $\mathrm{~Hz}$ & $\begin{array}{l}\text { Borsatto et al. } \\
\text { (2017) }\end{array}$ \\
\hline 13 & c.1330G >C (p.Asp444His) & c.1330G $>$ C (p.Asp444His) & $\mathrm{Hz}$ & 3.0 & $\mathrm{~Hz}$ & $\begin{array}{l}\text { Borsatto et al. } \\
\text { (2017) }\end{array}$ \\
\hline 14 & c.1330G >C (p.Asp444His) & c.1330G >C (p.Asp444His) & $\mathrm{Hz}$ & 2.8 & $\mathrm{~Hz}$ & $\begin{array}{l}\text { Borsatto et al. } \\
\quad \text { (2014) }\end{array}$ \\
\hline 15 & c. $1330 \mathrm{G}>\mathrm{C}$ (p.Asp444His) & c.1330G $>$ C (p.Asp444His) & $\mathrm{Hz}$ & 2.6 & $\mathrm{~Hz}$ & $\begin{array}{l}\text { Borsatto et al. } \\
\text { (2017) }\end{array}$ \\
\hline 16 & c.1330G $>C$ (p.Asp444His) & c.1330G $>C$ (p.Asp444His) & $\mathrm{Hz}$ & 3.7 & $\mathrm{~Hz}$ & $\begin{array}{l}\text { Borsatto et al. } \\
\text { (2014) }\end{array}$ \\
\hline 17 & c. $1368 \mathrm{~A}>\mathrm{C}$ (p.Gln456His) & WT & $\mathrm{Hz}$ & 2.8 & $\mathrm{~Hz}$ & $\begin{array}{l}\text { Borsatto et al. } \\
\text { (2017) }\end{array}$ \\
\hline 18 & c.1413T >C (p.Tyr494Cys) & c.1629C $>$ A (p.Cys471Cys) & $\mathrm{Hz}$ & 4.0 & $\mathrm{~Hz}$ & $\begin{array}{l}\text { Borsatto et al. } \\
\text { (2017) }\end{array}$ \\
\hline 19 & c. $643 \mathrm{C}>\mathrm{T}$ (p.Leu215Phe) & WT & $\mathrm{Hz}$ & 3.4 & $\mathrm{~Hz}$ & $\begin{array}{l}\text { Borsatto et al. } \\
\text { (2017) }\end{array}$ \\
\hline 20 & c. $1595 \mathrm{C}>\mathrm{T}$ (p.Thr532Met) & WT & $\mathrm{Hz}$ & 2.9 & $\mathrm{~Hz}$ & $\begin{array}{l}\text { Borsatto et al. } \\
\quad \text { (2017) }\end{array}$ \\
\hline 21 & c. $1595 \mathrm{C}>\mathrm{T}$ (p.Thr532Met) & WT & $\mathrm{Hz}$ & 2.9 & $\mathrm{~Hz}$ & $\begin{array}{l}\text { Borsatto et al. } \\
\text { (2014) }\end{array}$ \\
\hline 22 & c. $364 \mathrm{~A}>\mathrm{G}$ (p.Arg122Gly) & WT & $\mathrm{Hz}$ & 3.8 & $\mathrm{~Hz}$ & $\begin{array}{l}\text { Borsatto et al. } \\
\text { (2014) }\end{array}$ \\
\hline 23 & $\begin{array}{c}\text { c. }[595 \mathrm{C}>\mathrm{A} ; 1413 \mathrm{~T}>\mathrm{C}] \\
\text { (p.Val199Met / p.Cys471Cys) }\end{array}$ & WT & $\mathrm{Hz}$ & 3.6 & $\mathrm{~Hz}$ & $\begin{array}{l}\text { Borsatto et al. } \\
\text { (2017) }\end{array}$ \\
\hline
\end{tabular}


Table 1 - Cont.

\begin{tabular}{|c|c|c|c|c|c|c|}
\hline Patient & Allele 1 & Allele 2 & $\begin{array}{l}\text { Expected BD } \\
\text { according } \\
\text { to genotype }\end{array}$ & $\begin{array}{c}\text { Biotinidase } \\
\text { activity } \\
(\mathrm{nmol} / \mathrm{min} / \mathrm{mL})\end{array}$ & $\begin{array}{c}\text { Type of BD } \\
\text { according to } \\
\text { enzyme activity }\end{array}$ & Reference \\
\hline $24^{\#}$ & WT & WT & Normal & 2.6 & $\mathrm{~Hz}$ & $\begin{array}{l}\text { Borsatto et al. } \\
\quad(2017)\end{array}$ \\
\hline $25^{\#}$ & WT & WT & Normal & 3.3 & $\mathrm{~Hz}$ & $\begin{array}{l}\text { Borsatto et al. } \\
\text { (2017) }\end{array}$ \\
\hline $26^{\#}$ & WT & WT & Normal & 4.1 & $\mathrm{~Hz}$ & $\begin{array}{l}\text { Borsatto et al. } \\
\quad(2014)\end{array}$ \\
\hline $27^{\#}$ & WT & WT & Normal & 3.7 & $\mathrm{~Hz}$ & $\begin{array}{l}\text { Borsatto et al. } \\
\qquad(2014)\end{array}$ \\
\hline $28^{\#}$ & c.1330G >C (p.Asp444His) & WT & Normal & 3.5 & $\mathrm{~Hz}$ & In this study \\
\hline $29^{\#}$ & c. $1368 \mathrm{~A}>\mathrm{C}$ (p.Gln456His) & WT & Normal & 2.8 & $\mathrm{~Hz}$ & $\begin{array}{l}\text { Borsatto et al. } \\
\qquad(2017)\end{array}$ \\
\hline $30^{\#}$ & c.1330G >C (p.Asp444His) & c. $1284 C>$ T (p.Tyr428Tyr) & Normal & 4.4 & $\mathrm{~Hz}$ & $\begin{array}{l}\text { Borsatto et al. } \\
\quad \text { (2017) }\end{array}$ \\
\hline $31^{\#}$ & c.1330G >C (p.Asp444His) & WT & Normal & 3.8 & $\mathrm{~Hz}$ & $\begin{array}{l}\text { Borsatto et al. } \\
\quad \text { (2014) }\end{array}$ \\
\hline $32^{\#}$ & c. $1330 \mathrm{G}>\mathrm{C}$ (p.Asp444His) & WT & Normal & 3.1 & $\mathrm{~Hz}$ & $\begin{array}{l}\text { Borsatto et al. } \\
\quad(2014)\end{array}$ \\
\hline $33^{\#}$ & WT & c.1330G $>$ C (p.Asp444His) & Normal & 4.2 & $\mathrm{~Hz}$ & $\begin{array}{l}\text { Borsatto et al. } \\
\text { (2017) }\end{array}$ \\
\hline 34 & c.1330G >C (p.Asp444His) & WT & Partial & 2.1 & Partial/Hz & $\begin{array}{l}\text { Borsatto et al. } \\
\text { (2017) }\end{array}$ \\
\hline 35 & c. $1368 \mathrm{~A}>\mathrm{C}$ (p.Gln456His) & WT & Partial & 2.1 & Partial/Hz & $\begin{array}{l}\text { Borsatto et al. } \\
\qquad(2017)\end{array}$ \\
\hline 36 & c. $[755 \mathrm{~A}>\mathrm{G} ; 1330 \mathrm{G}>\mathrm{C}]^{*}$ & p.Asp252Gly / p.Asp444His* & Partial & 2.2 & Partial/Hz & $\begin{array}{l}\text { Borsatto et al. } \\
\text { (2017) }\end{array}$ \\
\hline 37 & c.1330G >C (p.Asp444His) & c. $479 \mathrm{G}>$ A (p.Cys160Tyr) & $\operatorname{Partial} / \mathrm{Hz}$ & 2.3 & Partial/Hz & In this study \\
\hline 38 & c.1330G >C (p.Asp444His) & c.1330G $>$ C (p.Asp444His) & $\mathrm{Hz}$ & 2.2 & Partial/Hz & $\begin{array}{l}\text { Borsatto et al. } \\
\text { (2017) }\end{array}$ \\
\hline 39 & c.1330G >C (p.Asp444His) & c.1330G $>$ C (p.Asp444His) & $\mathrm{Hz}$ & 2.3 & Partial/Hz & $\begin{array}{l}\text { Borsatto et al. } \\
\text { (2017) }\end{array}$ \\
\hline 40 & c.1330G >C (p.Asp444His) & c.1330G $>$ C (p.Asp444His) & $\mathrm{Hz}$ & 2.2 & Partial/Hz & $\begin{array}{l}\text { Borsatto et al. } \\
\text { (2017) }\end{array}$ \\
\hline 41 & c.1330G >C (p.Asp444His) & c.1330G >C (p.Asp444His) & $\mathrm{Hz}$ & 2.3 & $\operatorname{Partial} / \mathrm{Hz}$ & $\begin{array}{l}\text { Borsatto et al. } \\
\text { (2017) }\end{array}$ \\
\hline 42 & c.1330G>C (p.Asp444His) & c.1330G >C (p.Asp444His) & $\mathrm{Hz}$ & 2.3 & Partial/Hz & In this study \\
\hline 43 & c.278A>G (p.Tyr93Cys) & c. $1330 \mathrm{G}>\mathrm{C}$ (p.Asp444His) & $\mathrm{Hz}$ & 2.1 & Partial/Hz & In this study \\
\hline 44 & c.1330G >C (p.Asp444His) & c. $479 \mathrm{G}>$ A (p.Cys160Tyr) & $\mathrm{Hz}$ & 2.3 & Partial/Hz & $\begin{array}{l}\text { Borsatto et al. } \\
\text { (2014) }\end{array}$ \\
\hline 45 & c.1330G >C (p.Asp444His) & c. $1337 \mathrm{~T}>\mathrm{C}$ (p.Leu446Pro) & Unknown & 2.2 & Partial/Hz & $\begin{array}{l}\text { Borsatto et al. } \\
\text { (2017) }\end{array}$ \\
\hline 46 & c. $278 \mathrm{~A}>\mathrm{G}$ (p.Tyr93Cys) & WT & Unknown & 2.3 & Partial/Hz & In this study \\
\hline 47 & c. $278 \mathrm{~A}>\mathrm{G}$ (p.Tyr93Cys) & WT & Unknown & 2.2 & Partial/Hz & $\begin{array}{l}\text { Borsatto et al. } \\
\text { (2017) }\end{array}$ \\
\hline 48 & c. $278 \mathrm{~A}>\mathrm{G}$ (p.Tyr93Cys) & WT & Unknown & 2.2 & Partial/Hz & In this study \\
\hline 49 & c. $[595 \mathrm{G}>\mathrm{A} ; 1330 \mathrm{G}>\mathrm{C} ; 1629 \mathrm{C}>\mathrm{A}]^{*}$ & $\begin{array}{c}\text { p.Val199Met / p.Asp444Hist / } \\
\text { p.Cys471Cys* }\end{array}$ & Unknown & 2.2 & Partial/Hz & $\begin{array}{l}\text { Borsatto et al. } \\
\quad \text { (2017) }\end{array}$ \\
\hline 50 & WT & c. $278 \mathrm{~A}>\mathrm{G}$ (p.Tyr93Cys) & $\mathrm{Hz}$ & 2.2 & $\operatorname{Partial} / \mathrm{Hz}$ & $\begin{array}{l}\text { Borsatto et al. } \\
\text { (2017) }\end{array}$ \\
\hline 51 & c. $[755 \mathrm{~A}>\mathrm{G} ; 1330 \mathrm{G}>\mathrm{C}]^{*}$ & p.Asp252Gly / p.Asp444His* & $\mathrm{Hz}$ & 2.2 & $\operatorname{Partial} / \mathrm{Hz}$ & $\begin{array}{l}\text { Borsatto et al. } \\
\text { (2017) }\end{array}$ \\
\hline 52 & WT & c. $1368 \mathrm{~A}>\mathrm{C}$ (p.Gln456His) & $\mathrm{Hz}$ & 2.1 & $\operatorname{Partial} / \mathrm{Hz}$ & $\begin{array}{l}\text { Borsatto et al. } \\
\qquad(2017)\end{array}$ \\
\hline 53 & WT & c.1330G >C (p.Asp444His) & Normal & 4.9 & Hz/Normal & $\begin{array}{l}\text { Borsatto et al. } \\
\quad(2014)\end{array}$ \\
\hline 54 & WT & c.1330G $>$ C (p.Asp444His) & Normal & 4.9 & Hz/Normal & $\begin{array}{l}\text { Borsatto et al. } \\
\text { (2017) }\end{array}$ \\
\hline 55 & WT & c.1330G >C (p.Asp444His) & Normal & 4.9 & Hz/Normal & $\begin{array}{c}\text { Borsatto et al. } \\
\text { (2017) }\end{array}$ \\
\hline
\end{tabular}


Table 1 - Cont.

\begin{tabular}{|c|c|c|c|c|c|c|}
\hline Patient & Allele 1 & Allele 2 & $\begin{array}{l}\text { Expected BD } \\
\text { according } \\
\text { to genotype }\end{array}$ & $\begin{array}{c}\text { Biotinidase } \\
\text { activity } \\
(\mathrm{nmol} / \mathrm{min} / \mathrm{mL})\end{array}$ & $\begin{array}{c}\text { Type of BD } \\
\text { according to } \\
\text { enzyme activity }\end{array}$ & Reference \\
\hline 56 & WT & c.1330G $>$ C (p.Asp444His) & Normal & 4.9 & Hz/Normal & $\begin{array}{l}\text { Borsatto et al. } \\
\quad(2017)\end{array}$ \\
\hline 57 & WT & c.1330G $>$ C (p.Asp444His) & Normal & 4.9 & Hz/Normal & $\begin{array}{l}\text { Borsatto et al. } \\
\text { (2017) }\end{array}$ \\
\hline 58 & WT & c.1330G >C (p.Asp444His) & Normal & 4.9 & Hz/Normal & In this study \\
\hline 59 & c.1330G>C (p.Asp444His) & WT & Normal & 5.0 & Hz/Normal & $\begin{array}{l}\text { Borsatto et al. } \\
\text { (2017) }\end{array}$ \\
\hline 60 & c.1330G>C (p.Asp444His) & WT & Normal & 5.0 & Hz/Normal & In this study \\
\hline 61 & c.1330G >C (p.Asp444His) & WT & Normal & 5.0 & Hz/Normal & In this study \\
\hline 62 & WT & c. $1629 \mathrm{C}>\mathrm{A}$ (p.Cys471Cys) & Normal & 4.9 & Hz/Normal & $\begin{array}{l}\text { Borsatto et al. } \\
\quad(2014)\end{array}$ \\
\hline 63 & WT & c. $1629 \mathrm{C}>\mathrm{A}$ (p.Cys471Cys) & Normal & 5.0 & Hz/Normal & $\begin{array}{l}\text { Borsatto et al. } \\
\quad(2017)\end{array}$ \\
\hline 64 & c.1629C>A (p.Cys471Cys) & WT & Normal & 4.9 & Hz/Normal & $\begin{array}{l}\text { Borsatto et al. } \\
\text { (2017) }\end{array}$ \\
\hline 65 & c.1629C>A (p.Cys471Cys) & WT & Normal & 4.9 & Hz/Normal & $\begin{array}{l}\text { Borsatto et al. } \\
\text { (2014) }\end{array}$ \\
\hline 66 & c.1629C>A (p.Cys471Cys) & WT & Normal & 4.9 & Hz/Normal & In this study \\
\hline 67 & c.1629C>A (p.Cys471Cys) & WT & Normal & 4.9 & Hz/Normal & In this study \\
\hline 68 & WT & WT & Normal & 5.0 & Hz/Normal & $\begin{array}{l}\text { Borsatto et al. } \\
\text { (2017) }\end{array}$ \\
\hline 69 & c.1330G >C (p.Asp444His) & c.119T $>C$ (p.Leu40Pro) & Unknown & 1.7 & Partial & $\begin{array}{l}\text { Borsatto et al. } \\
\text { (2014) }\end{array}$ \\
\hline 70 & c.1330G>C (p.Asp444His) & c. $755 \mathrm{~A}>\mathrm{G}$ (p.Asp252Gly) & Partial & 1.9 & Partial & $\begin{array}{l}\text { Borsatto et al. } \\
\quad(2017)\end{array}$ \\
\hline 71 & c.1330G>C (p.Asp444His) & c.755A>G (p.Asp252Gly) & Partial & 1.4 & Partial & $\begin{array}{l}\text { Borsatto et al. } \\
\text { (2014) }\end{array}$ \\
\hline 72 & c.1330G>C (p.Asp444His) & c.755A>G (p.Asp252Gly) & Partial & 1.2 & Partial & $\begin{array}{l}\text { Borsatto et al. } \\
\quad(2014)\end{array}$ \\
\hline 73 & c.1330G >C (p.Asp444His) & c. $755 \mathrm{~A}>\mathrm{G}$ (p.Asp252Gly) & Partial & 1.8 & Partial & $\begin{array}{l}\text { Borsatto et al. } \\
\quad \text { (2017) }\end{array}$ \\
\hline 74 & c.755A>G (p.Asp252Gly) & c.1330G >C (p.Asp444His) & Partial & 1.4 & Partial & In this study \\
\hline 75 & c.1330G>C (p.Asp444His) & $\begin{array}{c}\text { c. }[511 \mathrm{G}>\mathrm{A} ; 1330 \mathrm{G}>\mathrm{C}] \\
\text { (p.Ala171Thr / p.Asp444His) }\end{array}$ & Partial & 1.4 & Partial & $\begin{array}{l}\text { Borsatto et al. } \\
\text { (2014) }\end{array}$ \\
\hline 76 & c.1330G >C (p.Asp444His) & $\begin{array}{c}\text { c. }[470 \mathrm{G}>\mathrm{A} ; 1330 \mathrm{G}>\mathrm{C}]( \\
\text { p.Arg157His / p.Asp444His })\end{array}$ & Partial & 1.8 & Partial & $\begin{array}{l}\text { Borsatto et al. } \\
\text { (2014) }\end{array}$ \\
\hline 77 & c.1330G >C (p.Asp444His) & $\begin{array}{c}\text { c. }[470 \mathrm{G}>\mathrm{A} ; 1330 \mathrm{G}>\mathrm{C}]( \\
\text { p.Arg157His / p.Asp444His })\end{array}$ & Partial & 1.9 & Partial & $\begin{array}{l}\text { Borsatto et al. } \\
\text { (2017) }\end{array}$ \\
\hline 78 & $\begin{array}{c}\text { c. }[1284 \mathrm{C}>\mathrm{T} ; 1489 \mathrm{C}>\mathrm{T}] \\
\text { (p.Tyr428Tyr / p.Pro497Ser) }\end{array}$ & c.1330G $>C$ (p.Asp444His) & Partial & 2.0 & Partial & $\begin{array}{l}\text { Borsatto et al. } \\
\text { (2017) }\end{array}$ \\
\hline 79 & c.1330G >C (p.Asp444His) & c.594_596del (p.Val199del) & Partial & 1.9 & Partial & $\begin{array}{l}\text { Borsatto et al. } \\
\text { (2014) }\end{array}$ \\
\hline 80 & c.1330G>C (p.Asp444His) & c.594_596del (p.Val199del) & Partial & 2.0 & Partial & $\begin{array}{l}\text { Borsatto et al. } \\
\quad \text { (2017) }\end{array}$ \\
\hline 81 & c.1330G >C (p.Asp444His) & c. $98 \_104 \mathrm{del}(\mathrm{fs})$ & Partial & 1.5 & Partial & $\begin{array}{l}\text { Borsatto et al. } \\
\text { (2014) }\end{array}$ \\
\hline 82 & c.1330G >C (p.Asp444His) & c. $98 \_104 \mathrm{del}(\mathrm{fs})$ & Partial & 1.6 & Partial & $\begin{array}{l}\text { Borsatto et al. } \\
\quad(2017)\end{array}$ \\
\hline 83 & c. $\left[98 \_104 \mathrm{del} ; 1330 \mathrm{G}>\mathrm{C}\right]^{*}$ & p.Cys33fs / p.Asp444His* & Partial & 2.0 & Partial & $\begin{array}{l}\text { Borsatto et al. } \\
\text { (2017) }\end{array}$ \\
\hline 84 & c. $[100 \mathrm{G}>\mathrm{A} ; 1330 \mathrm{G}>\mathrm{C}]^{*}$ & p.Gly34Ser / p.Asp444His* & Partial / Hz & 2.04 & Partial & $\begin{array}{l}\text { Borsatto et al. } \\
\quad(2014)\end{array}$ \\
\hline 85 & c. $1368 \mathrm{~A}>\mathrm{C}$ (p.Gln456His) & c.1330G $>C$ (p.Asp444His) & Partial & 2.0 & Partial & $\begin{array}{l}\text { Borsatto et al. } \\
\text { (2017) }\end{array}$ \\
\hline $86^{\#}$ & WT & c. $1330 \mathrm{G}>\mathrm{C}$ (p.Asp444His) & Normal & 1.2 & Partial & $\begin{array}{l}\text { Borsatto et al. } \\
\text { (2017) }\end{array}$ \\
\hline
\end{tabular}


Table 1 - Cont.

\begin{tabular}{|c|c|c|c|c|c|c|}
\hline Patient & Allele 1 & Allele 2 & $\begin{array}{c}\text { Expected BD } \\
\text { according } \\
\text { to genotype }\end{array}$ & $\begin{array}{c}\text { Biotinidase } \\
\text { activity } \\
(\mathrm{nmol} / \mathrm{min} / \mathrm{mL})\end{array}$ & $\begin{array}{c}\text { Type of BD } \\
\text { according to } \\
\text { enzyme activity }\end{array}$ & Reference \\
\hline $87^{\#}$ & WT & c. $1330 \mathrm{G}>\mathrm{C}$ (p.Asp444His) & Normal & 1.2 & Partial & $\begin{array}{l}\text { Borsatto et al } \\
\quad(2017)\end{array}$ \\
\hline 88 & $\begin{array}{c}\text { c. }[1330 \mathrm{G}>\mathrm{C} ; 1629 \mathrm{C}>\mathrm{A}] \\
\text { (p.Asp444His / p.Ala171Thr) }\end{array}$ & c. $1466 \mathrm{~A}>\mathrm{G}$ (p.Asn489Ser) & Unknown & 1.4 & Partial & $\begin{array}{l}\text { Borsatto et al } \\
\quad(2017)\end{array}$ \\
\hline 89 & c.643C $>$ T (p.Leu215Phe) & c. $755 \mathrm{~A}>\mathrm{G}$ (p.Asp252Gly) & Total & 0.04 & Total & $\begin{array}{l}\text { Borsatto et al } \\
\quad(2014)\end{array}$ \\
\hline 90 & c. $755 \mathrm{~A}>\mathrm{G}$ (p.Asp252Gly) & c. $755 \mathrm{~A}>\mathrm{G}$ (p.Asp252Gly) & Total & 0.44 & Total & $\begin{array}{l}\text { Borsatto et al } \\
\quad(2014)\end{array}$ \\
\hline 91 & c.1227_1241del (p.Trp409fs) & c.1227_1241del (p.Trp409fs) & Total & 0.09 & Total & $\begin{array}{l}\text { Borsatto et al } \\
\text { (2017) }\end{array}$ \\
\hline 92 & c. $1612 \mathrm{C}>\mathrm{T}$ (p.Arg538Cys) & c. $1612 \mathrm{C}>\mathrm{T}$ (p.Arg538Cys) & Total & 0.12 & Total & $\begin{array}{c}\text { Borsatto et al } \\
\quad(2014)\end{array}$ \\
\hline
\end{tabular}

$\mathrm{BD}=$ biotinidase deficiency WT - Wild Type fs = frameshift.

Normal reference range of the enzyme: $5.0 \pm 10 \mathrm{nmol} / \mathrm{min} / \mathrm{mL}$. The biochemical phenotype among patients who presented activity lower than $5.0 \mathrm{nmol} /$ $\mathrm{min} / \mathrm{mL}:<0.75(<10 \%)$, profound $\mathrm{BD} ; 0.75 \pm 2.25(10 \pm 30 \%)$, partial $\mathrm{BD}$; and $2.26 \pm 4.99(30.1 \pm 66.5 \%)$, heterozygous activity.

$*=$ Whether it is in cis or trans configuration with the other variant found remains undetermined.

\# = Patient with discrepancies between Expected BD according to genotype and Type of BD according to enzyme activity

and sequenced by Sanger method. Sequences were analyzed in the Chromas Lite software and aligned with the reference sequence NG_008019.1 in Blast/NCBI.

\section{In silico analysis}

Variants were searched in the $3^{\prime}$ UTR available in worldwide public genomic databases: LOVD (Fokkema et al., 2011 - 515,500 variants in 162,000 patients), gnomAD (Karczewski et al., 2020 - 76,156 genomes and 125,748 exomes), Online Archive of Brazilian Mutations - AbraOM (Naslavsky et al., 2017 - 1,171 genomes and 609 exomes) and Varsome clinical platform (Zhang et al., 2020 - 70 public genomic databases). Variants with rs snp code were classified according to the ACMG classification (Richards et al., 2015).

To evaluate conservation of the 3'UTR of BTD, sequence alignments between different species were performed in MEGA software (version 7.0.26, Kumar et al., 2016), using the ClustalW algorithm (version 2.1, Thompson et al., 1994). Evolutionarily conserved regions were mapped in ECR Browser (Ovcharenko et al., 2004). The chromosomal position provided in the Atlas of UTR Regulatory Activity (AURA) (Dassi et al., 2014) was used to locate the 3'UTR of BTD gene.

To investigate miRNAs that might regulate $B T D$ expression, mirBase (Kozomara and Griffiths-Jones, 2014) miRTarBase (Huang et al., 2019), TarBase (Karagkouni et al., 2017), TargetScanHuman (Agarwal et al., 2015), miRWalk (Dweep et al., 2011), and miRGate software (Andrés-León et $a l ., 2015)$ were used. To explore the shared miRNAs across the biotin metabolism related genes, the TopCluster web service (Kaimal et al., 2010) was used.

The miRanda (Enright et al., 2003), mirSVR (Betel et al., 2010), and microRNA.org (Betel et al., 2008) algorithms were used for analysis of miRNAs target sites associated with $B T D$. The cutoff points for this analysis were a binding free energy of $-25 \mathrm{Kcal}$ - proposed as more stable by Seffens and Digby (1999), and the search for evolutionarily conserved targets (mainly 8-mer), as suggested by Garcia et al. (2011).
For polyadenylation analysis, the constitutive site was characterized according to the reference sequence curated by NCBI. APADB (Müller et al., 2014), APASDB (You et al., 2015) databases and the PolyA_SVM (Structural Support Vector Machine) algorithm of the RegRNA package (v. 2.0, Chang et al., 2013) were used to quantify sites usage and polyadenylation signals.

To identify other regulatory elements in the 3'UTR, the software RegRNA v. 2.0 (Chang et al., 2013) and ARE Site 2 (Fallmann et al., 2015) were used. Secondary structures formed by miRNA-3'UTR interactions were obtained through the RNAfold Web server (Gruber et al., 2008).

\section{Results}

No variant was identified in the analysis of the $3^{\prime} \mathrm{UTR}$ of the BTD gene.

\section{In silico analysis}

Conservation analysis showed that the $3^{\prime} \mathrm{UTR}$ of the $B T D$ gene is highly conserved in primates. Alignments between the human vs. rat, mouse, cow, dog, rhesus monkey and chimpanzee 3'UTR sequences of BTD gene revealed identities of $73.1 \%, 71.6 \%, 70.6 \%, 72.1 \%, 94 \%$, and $99 \%$ respectively.

In the search of variants in genomic public databases, 43 variants were found in the AbraOM, 32 of them predicted as 'variant of uncertain significance' (VUS), and 11 as 'benign'. In the gnom $\mathrm{AD}$, nine variants were found, all predicted by the ACMG as 'VUS'. In the LOVD database, three variants were found - one predicted as 'VUS' and two as 'benign'. The allele frequencies and the respective rsSNP as shown in Table 2.

In silico analysis of miRNAs yielded highly variable results. The number of miRNAs predicted in BTD gene were: 51 in miRGate database, 35 in miRTarBase, 5 in miRWalk, 4 in TarBase and 2 in TargetScanHuman (Table 3).

Seven miRNA target sites (Table 4) and one RNA binding protein (Musashi Binding Element) were identified. The mapped elements were presented in Figure 2. 
Forty-nine miRNAs were associated with genes that interact with the BTD gene in biotin metabolism (Table 5). The only miRNA shared between $B T D$ and $H L C S$ was the hsa-miR-222.

The three best-predicted secondary structure models are presented in Figure 3. The most appropriate secondary structure according to RNAfold analysis was the model of interaction between the 3'UTR of the BTD gene and hsa-miR-3934, with a binding free energy of $-25.35 \mathrm{Kcal}$.

The polyadenylation signal used by the BTD gene coincides with the canonical AAUAAA hexamer. The dinucleotide that identifies the cleavage site was AA. Results from the APASdb database and the PolyA_SVM algorithm showed that the $B T D$ gene has two major mapped polyadenylation sites. The first signal begins at position 2044 and has $32 \mathrm{pb}$; the second signal begins at position 2329 and has $32 \mathrm{pb}$. According to the APADB database, both polyadenylation sites of the BTD gene are located in the 3'UTR at positions chr3:15687323 (86.1\% of usage) and chr3:15683749 (11.4\% of usage).

Six AU-rich elements were identified: TTTTT, ATTTA, ATTTT, TTTTA, TATTTTA and AATAAA.

Table 2 - 3'UTR variant frequencies in Brazilian genomic databases (ABraOM) and worldwide databases (gnomAD and LOVD).

\begin{tabular}{|c|c|c|c|c|}
\hline Database & Variant & rsSNP code & Prediction & Allele Frequency \\
\hline \multirow[t]{38}{*}{ ABraOM } & c. $* 83 \mathrm{~A}>\mathrm{T}$ & rs151091741 & Benign & 0.016652 \\
\hline & c. $* 96 \mathrm{G}>\mathrm{A}$ & rs530884413 & VUS & 0.000427 \\
\hline & c. $* 211 \mathrm{G}>\mathrm{A}$ & rs 78601074 & VUS & 0.002989 \\
\hline & c. $* 251 \mathrm{~T}>\mathrm{G}$ & rs973865557 & VUS & 0.000427 \\
\hline & c. $* 276 \mathrm{C}>\mathrm{T}$ & rs529324919 & VUS & 0.001708 \\
\hline & c. $* 310 \mathrm{~A}>\mathrm{G}$ & rs189885639 & VUS & 0.003843 \\
\hline & c. $* 348 \mathrm{G}>\mathrm{T}$ & rs187175217 & VUS & 0.007669 \\
\hline & c. $* 366 \mathrm{~A}>\mathrm{T}$ & rs1004621476 & VUS & 0.026046 \\
\hline & c. $* 368 \mathrm{C}>\mathrm{T}$ & rs1034718749 & VUS & 0.013237 \\
\hline & c. $* 371 \mathrm{G}>\mathrm{T}$ & rs960652511 & VUS & 0.017079 \\
\hline & c. $* 452 \mathrm{~A}>\mathrm{G}$ & rs79151199 & VUS & 0.002989 \\
\hline & c. $* 471 \mathrm{G}>\mathrm{T}$ & rs 115371875 & VUS & 0.005124 \\
\hline & c. $* 537 \mathrm{C}>\mathrm{T}$ & rs 180874910 & VUS & 0.005978 \\
\hline & c. $* 734 \mathrm{~A}>\mathrm{G}$ & rs 1019755479 & VUS & 0.000854 \\
\hline & c. $* 748 \mathrm{G}>\mathrm{C}$ & rs965102987 & VUS & 0.000427 \\
\hline & c. $* 549 \mathrm{C}>\mathrm{T}$ & rs572632251 & VUS & 0.000854 \\
\hline & c. $* 768 \mathrm{C}>\mathrm{T}$ & rs73150121 & VUS & 0.002989 \\
\hline & c. $* 573 \mathrm{G}>\mathrm{A}$ & rs965394624 & VUS & 0.000427 \\
\hline & c. $* 811 \mathrm{G}>\mathrm{A}$ & rs559860346 & VUS & 0.000854 \\
\hline & c. $* 847 \mathrm{~T}>\mathrm{A}$ & rs9647358 & Benign & 0.16567 \\
\hline & c. $* 916 \mathrm{G}>\mathrm{A}$ & rs1009938115 & VUS & 0.000854 \\
\hline & c. $* 903 \mathrm{G}>\mathrm{A}$ & rs57114474 & Benign & 0.094791 \\
\hline & c. $* 983 \mathrm{~T}>\mathrm{C}$ & rs76866504 & Benign & 0.015371 \\
\hline & c. $* 1009 \mathrm{~A}>\mathrm{G}$ & rs771654037 & VUS & 0.000854 \\
\hline & c. ${ }^{*} 1021 \mathrm{C}>\mathrm{T}$ & rs772800231 & VUS & 0.000854 \\
\hline & c. $* 1142 \mathrm{G}>\mathrm{A}$ & rs575407757 & VUS & 0.000427 \\
\hline & c. ${ }^{*} 1337 \mathrm{C}>\mathrm{T}$ & rs55866239 & Benign & 0.05807 \\
\hline & c. $* 1461 \mathrm{G}>\mathrm{T}$ & rs972571533 & VUS & 0.000427 \\
\hline & c. ${ }^{*} 1501 \mathrm{C}>\mathrm{T}$ & rs 117876477 & VUS & 0.002989 \\
\hline & c. ${ }^{*} 1546 \mathrm{~T}>\mathrm{C}$ & rs1041474484 & VUS & 0.000427 \\
\hline & c. $* 1059 \mathrm{~A}>\mathrm{G}$ & rs558313573 & VUS & 0.000854 \\
\hline & c. ${ }^{*} 1652 \mathrm{C}>\mathrm{T}$ & rs3796305 & Benign & 0.041418 \\
\hline & c. ${ }^{*} 1678 \mathrm{C}>\mathrm{T}$ & rs1027781482 & VUS & 0.000854 \\
\hline & c. ${ }^{*} 1686 \mathrm{C}>\mathrm{T}$ & rs145664140 & VUS & 0.002135 \\
\hline & c. ${ }^{*} 1693 \mathrm{C}>\mathrm{T}$ & rs 2455852 & Benign & 0.535013 \\
\hline & c. $* 1707 \mathrm{G}>\mathrm{A}$ & rs1017619524 & VUS & 0.000427 \\
\hline & c. $* 1763 \mathrm{C}>\mathrm{T}$ & rs 2470530 & Benign & 0.686166 \\
\hline & c. ${ }^{*} 1799 \mathrm{G}>\mathrm{A}$ & rs 3796302 & Benign & 0.094791 \\
\hline
\end{tabular}


Table 2 - Cont.

\begin{tabular}{|c|c|c|c|c|}
\hline Database & Variant & rsSNP code & Prediction & Allele Frequency \\
\hline & c. ${ }^{*} 1949 \mathrm{C}>\mathrm{T}$ & rs 1017670214 & VUS & 0.000427 \\
\hline & c. ${ }^{*} 2063 \mathrm{C}>\mathrm{T}$ & rs 73145546 & Benign & 0.026046 \\
\hline & c. $* 2106 \mathrm{G}>\mathrm{A}$ & rs915646184 & VUS & 0.000427 \\
\hline & c. $* 2121 \mathrm{C}>\mathrm{T}$ & rs 77633353 & VUS & 0.002135 \\
\hline & c. $* 2123 \mathrm{G}>\mathrm{A}$ & rs 2470531 & Benign & 0.532878 \\
\hline \multirow[t]{9}{*}{ gnomAD } & c. $* 8 \mathrm{G}>\mathrm{A}$ & rs773652007 & VUS & 0.000037 \\
\hline & c. ${ }^{*} 15 \mathrm{C}>\mathrm{T}$ & rs763033233 & VUS & 0.000103 \\
\hline & c. $* 23 \mathrm{C}>\mathrm{T}$ & rs766374135 & VUS & 0.000038 \\
\hline & c. $* 24 \mathrm{G}>\mathrm{A}$ & rs374047871 & VUS & 0.000080 \\
\hline & c. $* 29 \mathrm{C}>\mathrm{T}$ & rs1344267775 & VUS & 0.000008 \\
\hline & c. $* 32 \mathrm{G}>\mathrm{T}$ & rs 1200505812 & VUS & 0.000004 \\
\hline & c. $* 43 \mathrm{G}>\mathrm{T}$ & rs200147547 & VUS & 0.000030 \\
\hline & c. $* 53 \mathrm{C}>\mathrm{T}$ & rs761431603 & VUS & 0.000063 \\
\hline & c. $* 54 \mathrm{~A}>\mathrm{C}$ & rs 1404681940 & VUS & 0.000031 \\
\hline \multirow[t]{3}{*}{ LOVD } & c. $* 211 \mathrm{G}>\mathrm{A}$ & rs78601074 & VUS & 0.000358 \\
\hline & c. $* 847 \mathrm{~T}>\mathrm{A}$ & rs9647358 & Benign & 0.2132 \\
\hline & c. $* 2123 \mathrm{G}>\mathrm{A}$ & rs 2470531 & Benign & 0.5559 \\
\hline
\end{tabular}

Table 3 - miRNAs associated with the $B T D$ gene in different search methods and databases.

\begin{tabular}{|c|c|c|c|c|}
\hline miRGate & miRTarBase & miRWalk & TarBase & TargetScan \\
\hline hsa-mir-1227-3p & hsa-miR-10b-3p & hsa-miR-3620-3p & hsa-miR-129-2-3p & hsa-miR-145-5p \\
\hline hsa-mir-1233-5p & hsa-miR-1247-3p & hsa-miR-4743-3p & hsa-miR-200b-3p & hsa-miR-5195-3p \\
\hline hsa-mir-1266-5p & hsa-miR-1267 & hsa-miR-6499-3p & hsa-miR-21-3p & \\
\hline hsa-mir-1910-3p & hsa-miR-219b-3p & hsa-miR-6808-5p & hsa-miR-7-5p & \\
\hline hsa-mir-3127-5p & hsa-miR-30d-3p & hsa-miR-6837-3p & & \\
\hline hsa-mir-3137 & hsa-miR-30e-3p & & & \\
\hline hsa-mir-3158-3p & hsa-miR-340-5p & & & \\
\hline hsa-mir-3190-3p & hsa-miR-3620-3p & & & \\
\hline hsa-mir-3190-5p & hsa-miR-367-5p & & & \\
\hline hsa-mir-363-5p & hsa-miR-3929 & & & \\
\hline hsa-mir-3666 & hsa-miR-3942-3p & & & \\
\hline hsa-mir-4323 & hsa-miR-4257 & & & \\
\hline hsa-mir-4417 & hsa-miR-4419b & & & \\
\hline hsa-mir-4435 & hsa-miR-4478 & & & \\
\hline hsa-mir-4446-3p & hsa-miR-4649-3p & & & \\
\hline hsa-mir-4449 & hsa-miR-4652-3p & & & \\
\hline hsa-mir-4518 & hsa-miR-4670-3p & & & \\
\hline hsa-mir-4640-3p & hsa-miR-4722-5p & & & \\
\hline hsa-mir-4647 & hsa-miR-4729 & & & \\
\hline hsa-mir-4657 & hsa-miR-4743-3p & & & \\
\hline hsa-mir-4674 & hsa-miR-4768-3p & & & \\
\hline hsa-mir-4685-5p & hsa-miR-5100 & & & \\
\hline hsa-mir-4708-3p & hsa-miR-5584-3p & & & \\
\hline hsa-mir-4737 & hsa-miR-5696 & & & \\
\hline hsa-mir-4741 & hsa-miR-570-3p & & & \\
\hline hsa-mir-4758-3p & hsa-miR-579-3p & & & \\
\hline hsa-mir-485-5p & hsa-miR-6125 & & & \\
\hline hsa-mir-5001-3p & hsa-miR-6499-3p & & & \\
\hline
\end{tabular}


Table 3 - Cont.

\begin{tabular}{|c|c|c|c|c|}
\hline miRGate & miRTarBase & miRWalk & TarBase & TargetScan \\
\hline hsa-mir-5007-5p & hsa-miR-6516-5p & & & \\
\hline hsa-mir-505-3p & hsa-miR-664a-3p & & & \\
\hline hsa-mir-548q & hsa-miR-664b-3p & & & \\
\hline hsa-mir-603 & hsa-miR-6808-5p & & & \\
\hline hsa-mir-6511a-5p & hsa-miR-6893-5p & & & \\
\hline hsa-mir-6745 & hsa-miR-7160-5p & & & \\
\hline hsa-mir-6756-5p & hsa-miR-940 & & & \\
\hline \multicolumn{5}{|l|}{ hsa-mir-6764-5p } \\
\hline \multicolumn{5}{|l|}{ hsa-mir-6766-5p } \\
\hline \multicolumn{5}{|l|}{ hsa-mir-6798-3p } \\
\hline \multicolumn{5}{|l|}{ hsa-mir-6808-5p } \\
\hline \multicolumn{5}{|l|}{ hsa-mir-6811-3p } \\
\hline \multicolumn{5}{|l|}{ hsa-mir-6823-5p } \\
\hline \multicolumn{5}{|l|}{ hsa-mir-6833-5p } \\
\hline \multicolumn{5}{|l|}{ hsa-mir-6834-5p } \\
\hline \multicolumn{5}{|l|}{ hsa-mir-6837-5p } \\
\hline \multicolumn{5}{|l|}{ hsa-mir-6873-5p } \\
\hline \multicolumn{5}{|l|}{ hsa-mir-6882-3p } \\
\hline \multicolumn{5}{|l|}{ hsa-mir-6884-5p } \\
\hline \multicolumn{5}{|l|}{ hsa-mir-7114-5p } \\
\hline \multicolumn{5}{|l|}{ hsa-mir-718 } \\
\hline \multicolumn{5}{|l|}{ hsa-mir-874-5p } \\
\hline hsa-mir-938 & & & & \\
\hline
\end{tabular}

Table 4 - Prediction of miRNA target sites in BTD according to mirSVR and TargetScanHuman algorithms.

\begin{tabular}{lcccc}
\hline miRNA ID & mirSVR score & Phast Cons score & Type seed & Reference \\
\hline hsa-miR-6764-5p & 0.12 & 0.55 & 7 mer-m8 (1) 7mer-A1 (1) & Pathak et al. (2017) \\
hsa-miR-8066 & -1.29 & 0.52 & 7 mer-A1 (1) & Wang et al. (2013) \\
hsa-miR-940 & -0.01 & 0.44 & 8 mer (1) 6mer (1) & Rajendiran et al. (2014) \\
hsa-miR-1267 & -0.39 & 0.52 & 7 mer-m8 (2) & Tomasetti et al. (2016) \\
hsa-miR-5195-3p & -0.08 & 0.43 & 8 mer (2) 6mer (1) & Salehi et al. (2017) \\
hsa-miR-34a-5p & -0.01 & 0.44 & 7 mer-m8 (1) & Kálmán et al. (2014) \\
hsa-miR-1915-3p & -0.80 & 0.49 & 7 mer-m8 (1) & Migita et al. (2003) \\
\hline
\end{tabular}

mirSVR and Phast Cons score are related to conservation between the seed region of the miRNA and its target gene. The number in parentheses indicates how many sites of mRNA pairing:miRNA the detected algorithm.

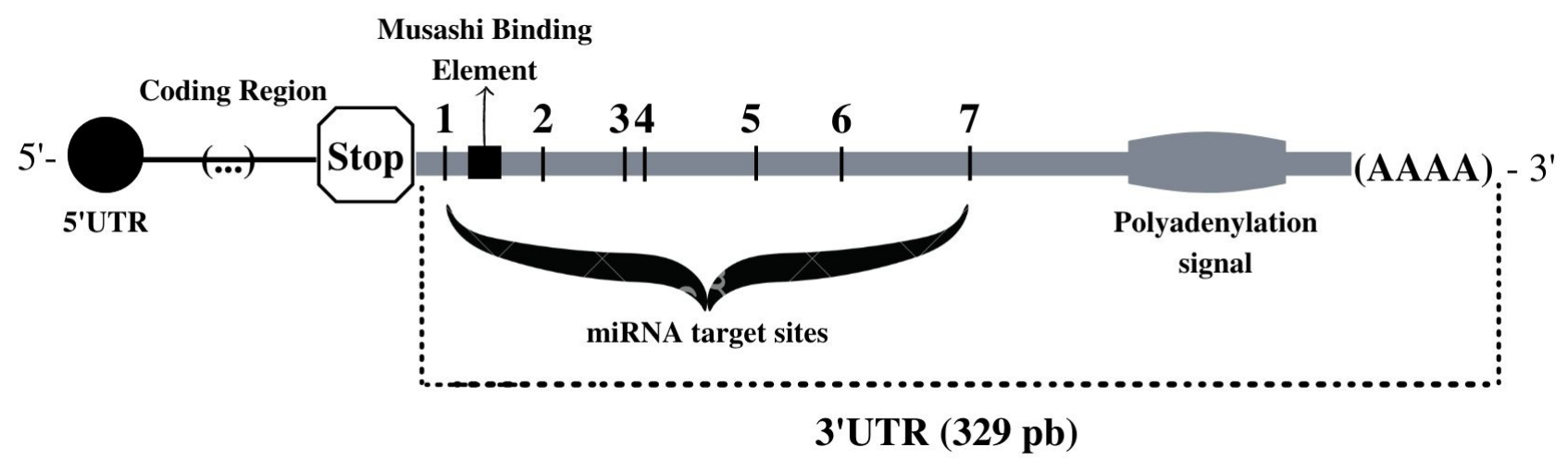

Figure 2 - Summary of the elements found associated with the 3'UTR of BTD. 
Table 5 - Genes involved in biotin metabolism and number of miRNAs predicted to influence the metabolic pathways of alanine, biotin, citrate and pyruvate.

\begin{tabular}{lcccc}
\hline Gene & Location & Name & miRNAs & Metabolism \\
\hline HLCS & $21 \mathrm{q} 22.1$ & Holocarboxylase Syntetase & Biotin \\
MCCC1 & $3 \mathrm{q} 27$ & $\begin{array}{c}\text { Methylcrotonoyl- Coenzyme A } \\
\text { carboxylase 1 (alfa) }\end{array}$ & 6 & Alanine, Biotin, \\
Ciotin & Pyruvate Carboxylase & 14 & 10 \\
SPCS1 & $11 \mathrm{q} 13.4$ & Signal Peptidase Complex subunit 1 & 11 & Biotin \\
SPCS3 & $3 \mathrm{p} 21.1$ & Signal Peptidase Complex subunit 3 & Biotin \\
\hline
\end{tabular}

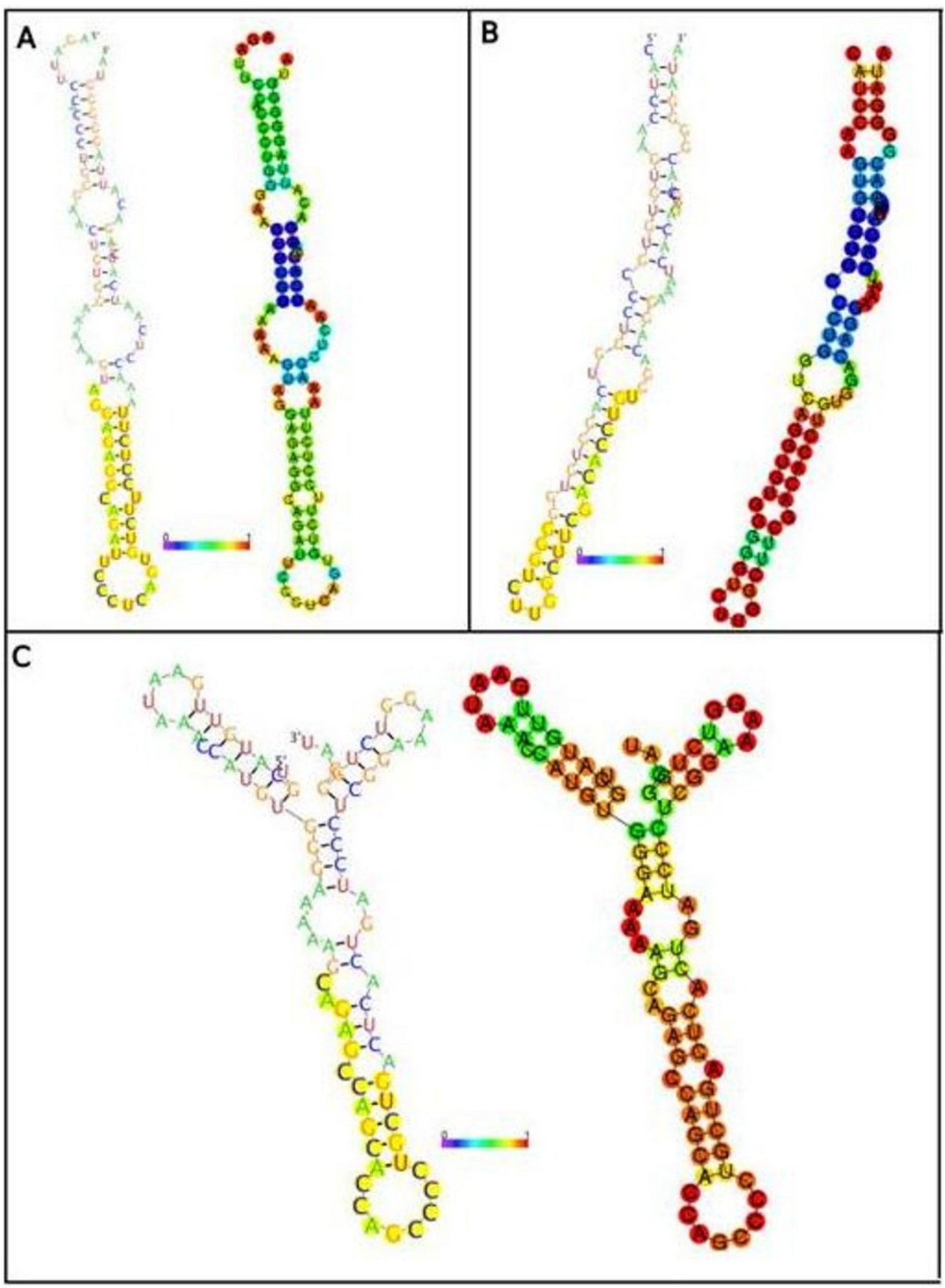

Figure 3 - Secondary structures of the miRNAs. A: miRNA hsa-miR-3916. B: miRNA hsa-miR-3934. C: miRNA hsa-miR-4763-5p. The yellow region shows the mature miRNA and the likelihood of them being associated with the BTD gene. The red color corresponds to the highest correlation between free energy binding between miRNA: mRNA and its interaction. 


\section{Discussion}

In this study, we investigated the presence of variants in the $3^{\prime} \mathrm{UTR}$ of the BTD gene in individuals with reduced biotinidase activity and, using bioinformatics tools, we discussed a possible relationship by regulatory elements with the expression of the $B T D$ gene.

As far as we know, the 3'UTR had never been characterized in patients. As observed in the present cohort about $20 \%$ of the patients have discrepancies between expected $\mathrm{BD}$ according to genotype and type of $\mathrm{BD}$ according to enzyme activity.

The hypothesis for this investigation came from other diseases that present phenotype modification due to variants in the 3'UTR of the affected gene, as Glycogen Storage Disease Ia (Karthi et al., 2017) and Haemophilia A (Rosset et al., 2016). Modified regulatory elements may affect the interaction of the UTRs with proteins and microRNAs causing modulation of mRNA transcription, secondary structure, stability, localization, translation, and access to regulators like microRNAs (miRNAs), RNA-binding proteins (RBPs) and justify the discrepancies between genotype and phenotype (Steri et al., 2018; Skarp et al., 2020).

The high conservation of the 3'UTR was observed among the 92 patients analyzed proved by the $100 \%$ homology - no variants were found. Variant databases reinforced the conservation of the region through low frequencies of variants.

Subsequent investigations of the 3'UTR found several miRNAs and elements present in the region. Variations present in patients could justify differences in gene expression through factors related to 3'UTR.

The main predicted miRNAs associated with the $B T D$ gene were: hsa-miR-7-5p, previously implicated in suppression of cell proliferation, induction of apoptosis, and angiogenesis (Li et al., 2016; Luo et al., 2018); hsa-miR-34a-5p, which is involved in cell proliferation and an important regulator of the central nervous system (Agostini and Knight, 2014; Jauhari and Yadav, 2019); and hsa-miR-145, identified in neonates and expressed specifically in the liver, where biotinidase expression is also higher (Fu et al., 2005; Noh et al., 2013).

The miR-7 cluster is known to be associated with genes related to the nervous system. Dostie et al. (2003) demonstrated that this miRNA may be unregulated in neuronal cells in spinal muscular atrophy, and involved in the neurological dysfunctions associated with Waisman Syndrome and Fragile $\mathrm{X}$ Syndrome. Untreated BD may lead to neurological problems and developmental delay. Thus, it is important to note that this miRNA, along with several potentially related factors, may be a candidate for investigation.

Hearing loss is a common sensorineural impairment in general populations. Experiments done in the inner ear of mice and humans have found differential expression of five miRNAs, among them miR-30, associated with different stages of ear development (Rudnicki and Avraham, 2012). In the present analysis, miR-30 was associated with the $B T D$ gene. Among patients with total $\mathrm{BD}, 75 \%$ of affected children have hearing loss (Wolf et al., 2002), with variable but usually irreversible severity.

Forty-nine miRNAs associated with genes that interact with the $B T D$ were identified in the biotin metabolic pathway. These miRNAs have already been implicated in cell signaling, glycosylation pathways, and in arginine, biotin, tyrosine, and thiamine metabolism (Ortega et al., 2010). The $P C$ gene that encodes pyruvate carboxylase, a biotin-dependent carboxylase, was found not only in the biotin metabolic pathway but also in alanine, citrate cycle, and pyruvate metabolic pathways (Rottiers and Näär, 2012).

Gene ontology analysis showed that these genes are involved in several biological processes, and act as coenzymes and in the metabolism of small molecules (Gene ontology: Fisher's exact with FDR multiple test correction: 9.95e-20 / 1.55e-15) (Thomas et al., 2003; Mi et al., 2013).

Among the most prominent results is the HLCS target gene. HLCS encodes the holocarboxylase synthetase that activates biotin-dependent carboxylases and catalyzes the binding of biotin to biotinidase. Experiments have shown that miR-539 decreases holocarboxylase synthetase levels, with the abundance of miR-539 being significantly higher at physiological biotin concentrations than in biotin-deficient and biotin-supplemented media, in all cell lines tested (Segura et al., 2013). The results of this study suggest that miR-539 may be one of several factors that detect biotin and regulate holocarboxylase synthetase levels. In the present study, this miRNA was not directly associated to the $B T D$ gene, but to the holocarboxylase synthetase gene $H L C S$.

The SPCS1 and SPCS3 genes - subunits of the peptidase signal complex that act as hydrolases and participate in degradation of lysine (Kailes and Hartmann, 1996) - also stood out. The lysine present in the biotin-lysine complex (biocytin) is believed to be degraded through the action of this complex. The miRNAs associated with these genes may have an impact on expression of SPCS1 and SPCS3 and, consequently, on lysine degradation, preventing biotin recycled into its free form. In addition, hsa-miR-204 and hsa-miR-211, both predicted to be associated with SPCS1, are implicated in mechanisms of cell proliferation and metastasis in several types of cancer, including breast, colon, and lung cancer (Mazar et al., 2010).

Esau et al. (2006) found that miR-122 allows the liver to function properly in adult mice. This miRNA is an important mechanism for regulation of genes involved in hepatic lipid metabolism. This corroborates the findings of Saha and Ruderman (2003) that observed negative effects on mice lipogenesis whereby a reduction in $A C C$ gene expression, particularly $A C C 2$, led to a decrease in malonyl CoA and subsequent increase in fatty acid oxidation. As biotinidase acts as a cofactor for several carboxylases, miRNAs may be involved in feedback regulation of this system. This miRNA was not found to be associated with $B T D$, but appears to be involved with citrate and pyruvate metabolism genes.

Based on the assumption that a single miRNA can regulate several target genes, $\mathrm{miR}-31-3 \mathrm{p}$ and miR-34a-5p were associated with the $B T D$ gene and with the $P C C A$ and $P C C B$ genes, which encode subunits of the enzyme propionyl-coA-carboxylase, one of the biotin-dependent carboxylases. Dysfunction in these genes can lead to propionic acidemia, a disease characterized mainly by neurological and cardiac damage. Rivera-Barahona et al. (2017) found that these miRNAs are deregulated in the liver of mice; more specifically, overexpression of the miR-34 family is observed in patients with cardiac involvement, and is associated with other neurodegenerative diseases. 


\section{Conclusions}

The present study was pioneer in the analysis of the 3'UTR of BTD gene in individuals with reduced biotinidase activity. Although the sequencing of this region has not found variants, it described their evolutive conservation.

The study of the 3'UTR in individuals with reduced biotinidase activity allowed us to conclude that variants in this region do not explain the genotype-phenotype discrepancies found in Brazilian patients. However, several factors as miRNAs sites and regulatory elements have been identified, which may influence the expression patterns of the BTD gene. To date, there are no strongly validated interactions between miRNAs and the BTD gene. Thus, its experimental validation remains as a perspective for future research.

\section{Acknowledgments}

This study was funded by the HCPA Research and Event Incentive Fund (FIPE) and the National Council for Scientific and Technological Development (CNPq). The authors would like to thank the staff at the HCPA Medical Genetics Service, with special thanks to those who provide care and follow-up of the patients included in the study.

\section{Conflict of Interests}

The authors report no conflicts of interest.

\section{Authors Contributions}

FSL and IVDS conceived and the study; GCVS and TB conducted the experiments; GCVS and TB analyzed the data; GCVS, FSL and IVDS wrote the manuscript and all authors read and approved the final version.

\section{References}

Agarwal V, Beel GW, Nam JW and Bartel DP (2015) Predicting effective microRNA target sites in mammalian mRNAs. eLife 4:e05005.

Agostini M and Knight RA (2014) miR-34: from bench to bedside. Oncotarget 5:872-881.

Andrés-León E, González Peña D, Gómez-López G and Pisano DG (2015) miRGate: a curated database of human, mouse and rat miRNA-mRNA targets. Database (Oxford) 2015:bav035.

Baumgartner MR and Suormala T (2012) Biotin-responsive Disorders. In: Saudubray JM, van den Berghe G and Walter JH (eds) Inborn Metabolic Diseases. Springer, Berlin, pp 375-384.

Betel D, Wilson M, Gabow A, Marks DS and Sander C (2008) The microRNA.org resource: targets and expression. Nucleic Acids Res 36:D149-D153.

Betel D, Koppal A, Agius P, Sander C and Leslie C (2010) Comprehensive modeling of microRNA targets predicts functional non-conserved and non-canonical sites. Genome Biol 11:R90.

Borsatto T, Sperb-Ludwig F, Pinto LL, De Luca GR, Carvalho FL, De Souza CF, De Medeiros PF, Lourenço CM, Lo Filho R, Eurico Neto C et al. (2014) Biotinidase deficiency: clinical and genetic studies of 38 Brazilian patients. BMC Med Genet 15:96.

Borsatto T, Sperb-Ludwig F, Lima SE, Carvalho MRS, Fonseca PAS, Camelo JS Jr, Ribeiro EM, Medeiros PFV, Lourenço CM, Souza CFM et al. (2017) Biotinidase deficiency: Genotypebiochemical phenotype association in Brazilian patients. PLoS One 12:e0177503.
Borsatto T, Sperb-Ludwig F, Blom HJ and Schwartz IVD (2019) Effect of $B T D$ gene variants on in vitro biotinidase activity. Mol Genet Metab 127:361-367.

Chang TH, Huang HY, Hsu JB, Weng SL, Horng JT and Huang HD (2013) An enhanced computational platform for investigating the roles of regulatory RNA and for identifying functional RNA motifs. BMC Bioinformatics 14:S4.

Dassi E, Re A, Leo S, Tebaldi T, Pasini L, Peroni L and Quattrone A (2014) Aura 2: Empowering discovery of post-transcriptional networks. Translation 2:e27738.

Dostie J, Mourelatos Z, Yang M, Sharma A and Dreyfuss G (2003) Numerous microRNPs in neuronal cells containing novel microRNAs. RNA 9:631-632.

Dweep H, Sticht C, Pandey P and Gretz N (2011) miRWalk-database: prediction of possible miRNA binding sites by "walking" the genes of three genomes. J Biomed Inf 44:839-847.

Enright AJ, John B, Gaul U, Tuschl T and Sander C (2003) MicroRNA targets in Drosophila. Genome Biol 5:R1.

Esau C, Davis S, Murray SF, Yu XX, Pandey SK, Pear M, Watts L, Booten SL, Graham M, McKay R et al. (2006) miR-122 regulation of lipid metabolism revealed by in vivo antisense targeting. Cell Metab 3:87-98.

Fallmann J, Sedlyarov V, Tanzer A, Kovarik P and Hofacker IL (2015) AREsite2: an enhanced database for the comprehensive investigation of AU/GU/U-rich elements. Nucleic Acids Res 44:D90-D95.

Fokkema IF, Taschner PE, Schaafsma GC, Celli J, Laros JF and den Dunnen JT (2011) LOVD v.2.0: the next generation in gene variant databases. Hum Mutat 32:557-563.

Fu H, Tie Y, Xu C, Zhang Z, Zhu J, Shi Y, Jiang H, Sun Z and Zheng $X$ (2005) Identification of human fetal liver miRNAs by a novel method. FEBS Lett 579:3849-3854.

Garcia DM, Baek D, Shin C, Bell GW, Grimson A and Bartel DP (2011) Weak seed-pairing stability and high targetsite abundance decrease the proficiency of 1sy-6 and other microRNAs. Nat Struct Biol 18:1139-1146.

Gruber AR, Lorenz R, Bernhart SH, Neuböck R and Hofacker IL (2008) The Vienna RNA Websuite. Nucleic Acids Res 66:W70-4.

Huang HY, Lin YCD, Li J, Huang KY, Shrestha S, Hong HC, Tang Y, Chen YG, Jin CN, Yu Y et al. (2019) miRTarBase 2020: updates to the experimentally validated microRNA-target interaction database. Nucleic Acids Res 48:D148-D154.

Jauhari A and Yadav S (2019) MiR-34 miR200: Regulator of cell fate plasticity and neural development. Neuromol Med 21:97-109.

Kailes KU and Hartmann E (1996) Membrane topology of the 12and the $25-\mathrm{kDa}$ subunits of the mammalian signal peptidase complex. J Biol Chem 271:3925-3929.

Kaimal V, Bardes EE, Tabar SC, Jegga AG and Aronow BJ (2010) ToppCluster: a multiple gene list feature analyzer for comparative enrichment clustering and network-based dissection of biological systems. Nucleic Acids Res 38: W96-W102.

Kálmán S, Garbett KA, Vereczkei A, Shelton RC, Korade Ž and Mirnics K (2014) Metabolic stress-induced microRNA and mRNA expression profiles of human fibroblasts. Exp Cell Res 320:343-353.

Karagkouni D, Paraskevopoulou MD, Chatzopoulos S, Vlachos IS, Tastsoglou S, Kanellos I and Hatzigeorgiou AG (2017) DIANA-TarBase v8: a decade-long collection of experimentally supported miRNA-gene interactions. Nucleic Acids Res 46:D239-D245.

Karczewski KJ, Francioli LC, Tiao G, Cummings BB, Alföldi J, Wang Q, Collins RL, Laricchia KM, Ganna A, Birnbaum DP et al. (2020) The mutational constraint spectrum quantified from variation in 141,456 humans. Nature 581:434-443. 
Karthi S, Rajeshwari M, Francis A, Saravanan M, Varalakshmi P, Houlden H, Thangaraj K and Ashokkumar B (2017) 3'-UTR SNP rs2229611 in G6PC1 affects mRNA stability, expression and Glycogen Storage Disease type-Ia risk. Clin Chim Acta 471:46-54.

Kozomara A and Griffiths-Jones S (2014) miRBase: annotating high confidence microRNAs using deep sequencing data. Nucleic Acids Res 42:68-73.

Kumar S, Stecher G and Tamura K (2016) MEGA 7: Molecular Evolutionary Genetics Analysis version 7.0 for bigger datasets. Mol Biol Evol 33:1870-1874.

Li Y, Wen L, Wei X, Wang Q-R, Xu L-R, Zhang H-M and Liu WC (2016) Inhibition of miR-7 promotes angiogenesis in human umbilical vein endothelial cells by upregulating VEGF via KLF4. Onco Rep 36:1569-1575.

Luo H, Liang H, Chen Y, Chen S, Xu Y, Xu L, Liu J, Zhou K, Peng J, Guo G et al. (2018) miR-7-5p overexpression suppresses cell proliferation and promotes apoptosis through inhibiting the ability of DNA damage repair of PARP-1 and BRCA1 in TK6 cells exposed to hydroquinone. Chem Biol Interact 283:84-90.

Mazar J, DeYoung K, Khaitan D, Meister E, Almodovar A, Goydos E, Ray A and Perera RJ (2010) The regulation of miRNA-211 expression and its role in melanoma cell invasiveness. PLoS One 5:e13779.

Mi H, Muruganujan A and Thomas PD (2013) PANTHER in 2013: modeling the evolution of gene function, and other gene attributes, in the context of phylogenetic trees. Nucleic Acids Res 41:377-386.

Migita K, Tanaka F, Abiru S, Ida H, Izumi Y, Kawakami A and Eguchi, K (2003) The role of mitochondria in nitric oxidemediated thymocyte apoptosis. Immunol Lett 90:87-91.

Müller S, Rycak L, Afonso-Grunz F, Winter P, Zawada AM, Damrath E, Scheider J, Schmah J, Koch I, Kahl G et al. (2014) APADB: a database for alternative polyadenylation and microRNA regulation events. Database (Oxford) 2014:bau076.

Naslavsky MS, Yamamoto GL, de Almeida TF, Ezquina SAM, Sunaga DY, Pho N, Bozoklian D, Sandberg TOM, Brito LA, Lazar M et al. (2017) Exomic variants of an elderly cohort of Brazilians in the ABraOM database. Hum Mut 38:751-763.

Noh JH, Chang YG, Kim MG, Jung KH, Kim JK, Bae HJ, Eun JW, Shen Q, Kim SJ, Kwon Sh et al. (2013) MiR-145 functions as a tumor suppressor by directly targeting histone deacetylase 2 in liver cancer. Cancer Lett 335:455-462.

Ortega FJ, Moreno-Navarrete JM, Pardo G, Sabater M, Hummel M, Ferrer A, Rodriguez-Hermosa JI, Ruiz B, Ricart W, Peral B et al. (2010) MiRNA expression profile of human subcutaneous adipose and during adipocyte differentiation. PLoS One 5:e9022.

Ovcharenko I, Nóbrega MA, Loots GG and Stubbs L (2004) ECR Browser: a tool for visualizing and accessing data from comparisons of multiple vertebrate genomes. Nucleic Acids Res 32:280-286.

Pathak E, Bhavya DM, Atri N and Mishra R (2017) Deciphering the role of microRNAs in BRD4-NUT fusion gene induced NUT midline carcinoma. Bioinformation 13:209.

Pindolia K, Jensen K and Wolf B (2007) Three dimensional structure of human biotinidase: computer modeling and functional correlations. Mol Genet Metab 92:13-22.

Pindolia K, Jordan M and Wolf B (2010) Analysis of mutations causing biotinidase deficiency. Hum Mutat 31:983-991.

Rajendiran S, Parwani AV, Hare RJ, Dasgupta S, Roby RK and Vishwanatha JK (2014) MicroRNA-940 suppresses prostate cancer migration and invasion by regulating MIEN1. Mol Cancer 13:250.
Richards S, Aziz N, Bale S, Bick D, Das S, Gastier-Foster J, Grody WW, Hegde M, Lyon E, Spector E et al. (2015) Standards and guidelines for the interpretation of sequence variants: a joint consensus recommendation of the American College of Medical Genetics and Genomics and the Association for Molecular Pathology. Genet Med 17:405-424.

Rivera-Barahona A, Fulgencio-Covian A, Perez-Cerda C, Ramos R, Barry MA, Ugarte M, Perez B, Richard E and Desviat LR (2017) Dysregulated miRNAs and their pathogenic implications for the neurometabolic disease propionic academia. Sci Rep 7:5727.

Rosset C, Vieira IA, Salzano FM and Bandinelli E (2016) A germline variant affects putative miRNA-binding sites at the F8 3'UTR and acts as a potential haemophilia A phenotype modifier in Southern Brazilian patients. Haemophilia 22:e327-329.

Rottiers V and Näär AM (2012) MicroRNAs in metabolism and metabolic disorders. Nat Rev. Mol Cell Biol 13:239-250.

Rudnicki A and Avraham KB (2012) microRNAs: the art of silencing in the ear. EMBO Mol Med 4:849-859.

Saha AK and Ruderman NB (2003) Malonyl-CoA and AMPactivated protein kinase: an expanding partnership. Mol Cell Biochem 253:65-70.

Salehi Z and Akrami H (2017) Target genes prediction and functional analysis of microRNAs differentially expressed in gastric cancer stem cells MKN-45. J Can Res Ther 13:477.

Seffens W and Digby D (1999) mRNAs have greater negative folding free energies than shuffled or codon choice randomized sequences. Nucleic Acids Res 27:1578-1584.

Segura LG, Andrade MP and Ríos JM (2013) The emerging role of microRNAs in the regulation of gene expression by nutrients. J Nutrigenet Nutrigenom 6:16-31.

Skarp S, Xia JH, Zhang Q, Löija M, Costantini A, Ruddock LW and Männikkö M (2020) Exome sequencing reveals a phenotype modifying variant in ZNF528 in primary osteoporosis with a COL1A2 deletion. J Bone Miner Res 35:2381-2392.

Stanley CM, Hymes J and Wolf B (2004) Identification of alternatively spliced human biotinidase mRNAs and putative localization of endogenous biotinidase. Mol Genet Metab 81:300-312.

Steri M, Idda ML, Whalen MB and Orrù V (2018) Genetic variants in mRNA untranslated regions. RNA 9:e1474.

Thomas PD, Campbell MJ, Kejariwal A, Mi H, Karlak B, Daverman R, Diemer K, Muruganujan A and Narechania A (2003) PANTHER: A library of protein families and subfamilies indexed by function. Genome Res 13:2129-2141.

Tomasetti M, Amati M, Santarelli L and Neuzil J (2016) MicroRNA in metabolic re-programming and their role in tumorigenesis. Int J Mol Sci 17:754

Thompson JD, Higgins DG and Gibson DJ (1994) CLUSTAL W: improving the sensitivity of progressive multiple sequence alignment through sequence weighting, position-specific gap penalties and weight matrix choice. Nucleic Acids Res 11:4673-4680.

Wang HJ, Zhang PJ, Chen WJ, Jie D, Dan F, Jia YH and Xie LX (2013) Characterization and Identification of novel serum microRNAs in sepsis patients with different outcomes. Shock 39:480-487.

Wastell HJ, Bartlett K, Dale G and Shein A (1988) Biotinidase deficiency: a survey of 10 cases. Arch Dis Child 63:1244-1249.

Wolf B (2001). Disorders of biotin metabolism. In: Scriver CR, Beaudet AL, Sly WS and Valle D (eds) The metabolic and molecular bases of inherited disease 8th edition, McGrawHill, New York, pp 3935-3962. 
Wolf B, Spencer RF and Gleason AT (2002) Hearing loss in common in symptomatic children with profound biotinidase deficiency. J Pediatr 140:242-246.

You L, Wu J, Feng Y, Fu Y, Guo Y, Long L, Zhang H, Luan Y, Tian P, Chen L et al. (2015) APASdb: a database describing alternative poly(A) sites and selection of heterogeneous cleavage sites downstream of poly(A) signals. Nucleic Acids Res 43:59-67.
Zhang J, Yao Y, He H and Shen J (2020) Clinical interpretation of sequence variants. Curr Protoc Hum Genet 106:e98.

Associate Editor: Maria Angélica Cortez

License information: This is an open-access article distributed under the terms of the Creative Commons Attribution License (type CC-BY), which permits unrestricted use, istribution and reproduction in any medium, provided the original article is properly cited. 